\title{
Predição do transtorno emocional em trabalhadores a partir do suporte organizacional e assédio moral no trabalho
}

\author{
Prediction of emotional disorder in workers from organizational support and workplace bullying \\ Predicción de trastorno emocional en trabajadores por apoyo organizacional y acoso laboral
}

Recebido: 02/06/2021 | Revisado: 09/06/2021 | Aceito: 10/06/2021 | Publicado: 23/06/2021

\author{
Nilton S. Formiga \\ ORCID: https://orcid.org/0000-0003-4907-9736 \\ Universidade Potiguar, Brasil \\ E-mail: nsformiga@yahoo.com \\ Juliana Bianca Maia Franco \\ ORCID: https://orcid.org/0000-0002-7566-2688 \\ Universidade Potiguar, Brasil \\ E-mail: juliana_franco_@hotmail.com \\ Heitor César Costa Oliveira \\ ORCID: https://orcid.org/ 0000-0003-4778-6613 \\ Universidade Potiguar, Brasil \\ E-mail: cartoriosbrasil@gmail.com \\ Ismael de Mendonça Azevedo \\ ORCID: https://orcid.org/0000-0002-1695-3522 \\ Universidade Potiguar, Brasil \\ E-mail: ismaeldemendonca@bol.com.br \\ Luana Araújo Matos \\ ORCID: https://orcid.org/0000-0003-0396-2312 \\ Universidade Potiguar, Brasil \\ E-mail: matosluana @hotmail.com \\ Tarciara Magley da Fonseca Pereira \\ ORCID: https://orcid.org/0000-0002-7570-8471 \\ Universidade Potiguar, Brasil \\ E-mail: tarciara@ufersa.edu.br \\ Fábio da Silva \\ ORCID: https://orcid.org/0000-0003-0039-0128 \\ Universidade Potiguar, Brasil \\ E-mail: fabiosoyme@hotmail.com
}

\begin{abstract}
Resumo
Com as mudanças ocorrias no mundo do trabalho nos últimos anos, tem exigido que organizações e trabalhadores modifiquem suas estratégias de atuação visando maior eficiência e produtividade com menor adoecimento laboral. Neste contexto, a gestão tem incentivado seus talentos a se reinventarem, condição a qual, poderá intensificar pressões no ritmo de trabalho e responsabilidades tornando precário os processos de trabalho, colocando em risco a saúde do trabalhador, especialmente, no que se refere ao transtorno mental. Sendo assim, tais exigências, seja de forma sutil ou não, consciente ou não, poderá se inserir num processo de humilhação e na criação de baixo vínculo do trabalhador com a organização. Com isso, o presente artigo tem como objetivo avaliar o quanto o suporte organizacional e ao assédio moral influenciaria no transtorno mental leve no ambiente de trabalho. Participaram do estudo, 212 trabalhadores, com idades variando de 20 a 67 anos, a maioria do setor privado, mulheres, com estado civil casadas e com uma média de 9,19 anos de tempo de serviço. As análises dos dados referentes análise descritivas realizadas no SPSSWIN, em sua versão 24.0, foram: alfa de Cronbach, regressão linear e ANOVA. Observou-se que as escalas utilizadas apresentaram indicadores psicométricos confiáveis para a referida amostra e que a hipótese relativa ao suporte organizacional, assédio moral no trabalho quanto preditores, do transtorno emocional foram confirmadas, bem como, no cálculo da Anova, aqueles que apresentaram escores no baixo suporte organizacional e maior no assédio moral, provavelmente, apresentará maior transtorno emocional (ansiedade, depressão e estresse). Com base nestes resultados, uma dinâmica organizacional que tenha um menor apoio e/ou conduza o trabalhado ao baixo vínculo laboral, poderá contribuir para o assédio moral, qual influenciará no surgimento do transtorno emocional.
\end{abstract}

Palavras-chave: Suporte organizacional; Assédio moral; Transtorno emocional; Trabalhadores. 


\begin{abstract}
The changes that have occurred in the world of work in recent years have required organizations and workers to modify their strategies of action aiming at greater efficiency and productivity with less working illness. In this context, management has encouraged their talents to reinvent themselves, a condition which may intensify pressures on the workplace pace and responsibilities, by making work processes precarious and putting workers' health at risk, especially with regard to mental disorder. Thus, such demands, whether subtle or not, conscious or not, may be inserted in a process of humiliation and in the creation of a low bond between the worker and the organization. In this way, the present article aims to assess how much organizational support and bullying would influence mild mental disorder in the workplace. A number of 212 workers at ages varying from 20 to 67 participated in the study, most of them from the private sector, women, with married marital status and having an average of 9.19 years of service. The data analysis, referring to descriptive analysis performed in SPSSWIN in its version 24.0, were: Cronbach's alpha, linear regression and ANOVA. It was observed that the scales used presented reliable psychometric indicators for the referred sample and that the hypothesis related to organizational support, bullying at work and predictors of emotional disorder were confirmed, as well as, in the ANOVA calculation, those who presented scores in the low organizational support and higher scores in bullying are likely to present higher-order emotional disorders (anxiety, depression and stress). Based on these results, an organizational dynamic that has less support and/or leads the employee to a low employment relationship may contribute to moral harassment, which will influence the emergence of the emotional disorder.
\end{abstract}

Keywords: Organizational support; Moral harassment; Emotional disorder; Workers.

\begin{abstract}
Resumen
Con los cambios que se han producido en el mundo del trabajo en los últimos años, se ha requerido que las organizaciones y los trabajadores modifiquen sus estrategias de acción apuntando a una mayor eficiencia y productividad con menos enfermedades en el trabajo. En este contexto, la dirección ha animado a sus talentos a reinventarse, condición que puede intensificar las presiones sobre el ritmo de trabajo y las responsabilidades, haciendo precarios los procesos laborales, poniendo en riesgo la salud de los trabajadores, especialmente en lo que respecta al trastorno mental. Así, tales demandas, sutiles o no, conscientes o no, pueden insertarse en un proceso de humillación y en la creación de un bajo vínculo entre el trabajador y la organización. Por lo tanto, este artículo tiene como objetivo evaluar en qué medida el apoyo organizacional y el acoso influirían en el trastorno mental leve en el lugar de trabajo. En el estudio participaron 212 trabajadores, con edades comprendidas entre los 20 y los 67 años, la mayoría del sector privado, mujeres, con estado civil casado y con una media de 9,19 años de servicio. Los análisis de los datos referentes al análisis descriptivo, alfa de Cronbach, regresión lineal y ANOVA se realizaron con SPSSWIN, en su versión 24.0. Se observó que las escalas utilizadas presentaron indicadores psicométricos confiables para la muestra referida y que se confirmaron las hipótesis relacionadas con el apoyo organizacional, "bullying" en el trabajo y predictores de trastorno emocional, así como, en el cálculo del ANOVA, aquellos que presentaron puntajes en el un bajo apoyo organizacional y un mayor bullying pueden presentar mayores trastornos emocionales (ansiedad, depresión y estrés). Con base en estos resultados, una dinámica organizacional que tenga menos apoyos y / o lleve al empleado a una relación laboral baja, puede contribuir al acoso moral, lo que incidirá en la aparición del trastorno emocional.
\end{abstract}

Palabras clave: Apoyo organizacional; Acoso moral; Trastorno emocional; Trabajadores.

\title{
1. Introdução
}

O ambiente de trabalho norteado pelas mudanças tecnológicas, socioeconômicas e políticas está exigindo que as organizações modifiquem estrategicamente sua forma de atuação para que se tornem mais eficientes e empreendedoras, de um lado, e ao mesmo tempo, mais receptivas às pressões institucionais para uma conduta mais ética e justa, por outro lado. Nesse cenário, a globalização aumentou drasticamente a rivalidade entre as organizações, impulsionando as empresas a tornarem-se mais eficientes - buscando maneiras de reduzir custos, aumentar receitas e ampliar a produtividade - para melhor enfrentar a concorrência - procurando reduzir preços e melhorar a qualidade (Diógenes, Paschoal, Neive \& Meneses, 2016).

Em sintonia com este fato, há no mundo uma forte transição e mudança, em que a competitividade é a base fundamental do sucesso, por isto, as organizações de hoje requerem contínua mudança interna, inovação e renovação para permanecerem surfando sobre as ondas intranquilas do oceano de transformações rápidas e sucessivas do mundo organizacional (McShane \& Glinow, 2013). Por isso, as organizações e seus gestores incentivam seus colaboradores de forma obrigatória a reinventar-se junto aos processos de trabalho e seus talentos humanos. Nesse sentido, pode se afirmar que cada 
vez mais as empresas buscam no mercado, tais talentos humanos para fazer o diferencial diante da concorrência (Tagliapietra, 2015).

Em uma nova abordagem da perspectiva da gestão pessoas, diz que os chamados talentos humanos, podem desenvolver de forma atrativa e gerir a manutenção de competências prioritárias, que atendam aos objetivos estabelecidos pela organização, com isso, dois tipos de atividades poderão ser geradas nas rotinas profissionais: as atividades que são obrigatórias de acordo com a função que ocupam, pré-estabelecidas no contrato social e as atividades que são realizadas voluntariamente, as quais, têm a intenção de colaborar com a organização e pares de iguais no ambiente de trabalho, que pode ser chamado de contrato psicológico (cf. Fleury \& Fleury, 2004; Nunes, 2017).

Nesse cenário, considerando, assim, o pressuposto da existência de uma relação de troca social, seja ela implícita ou não, entre os talentos humanos e a organização, se e somente se, houver um ambiente favorável; em que o trabalhador crie vínculos afetivos positivos de satisfação e envolvimento que refletem no seu bem-estar no ambiente de trabalho (cf. Siqueira, 2003; Sobrinho \& Porto, 2012).

É possível que o comportamento e a reciprocidade desses talentos para a organização indiquem ser favorável quando percebem que a empresa lhes oferece Suporte Organizacional, isto é, se preocupam com os seus funcionários. Não apenas sugere o foco na qualidade de vida do trabalhador e da empresa, mas, também, a saúde geral deste (Prado, 2005; Bertoncello \& Borges-Andrade, 2015; Estivalete, Andrade, Faller, Stefanan, \& Souza, 2016). Nessa circunstância, segundo a Lei no 8.080/90 (Brasil, 1990), compreende-se por saúde do trabalhador um conjunto de atividades que se destina, por meio de ações de vigilância epidemiológica e de vigilância sanitária, à promoção e à proteção da saúde dos trabalhadores, assim como visa à recuperação e à reabilitação da saúde dos trabalhadores submetidos aos riscos e aos agravos advindos das condições de trabalho, abrangendo diversas ações.

Nessa perspectiva, todas essas transformações no mundo do trabalho passaram a deixar suas marcas diretamente na saúde do trabalhador, revelada através da reestruturação produtiva, com a intensificação das pressões, do ritmo de trabalho, o excesso de responsabilidades, precarização na organização e nos processos de trabalho, entre outros fatores que podem vir a colocar em risco a saúde do trabalhador. Sendo uma das principais consequências para a saúde do trabalhador foi o aumento nos casos em que o trabalho foi agente causador de transtorno mental (Bardini, 2017).

Já os conceitos de saúde mental se modificam a partir do momento em que se verificam transtornos mentais em diversas populações, demonstrando que ter algum tipo de transtorno mental não é um castigo divino, como se acreditava na antiguidade, mas sim, fruto de fatores genéticos, sociais e culturais (Sá Junior, 2004). Sendo assim, ainda elucida que se faz necessário analisar como tem sido realizado o estabelecimento do nexo causal entre os transtornos mentais e o trabalho, ou seja, quando há relação entre o sofrimento psíquico e as atividades laborais do trabalhador (Bardini, 2017).

Nesse conjunto, os transtornos mentais têm sua etiologia multicausal, cujos fatores se correlacionam de modo bastante complexo. Daí a relevância de uma investigação diagnóstica, em que a anamnese ocupacional é o instrumento decisivo (Merlo, Bottega \& Perez, 2014). Por isso, indicam alguns aspectos fundamentais para a detecção da relação dos sinais e sintomas psíquicos com o trabalho. Ou seja, no tocante ao nexo causal com a saúde mental, a contribuição do trabalho para a alteração da saúde do trabalhador se dá por meio de uma série de variáveis, desde fatores específicos, como a exposição a agentes tóxicos até aos fatores relativos à condição e organização do trabalho, como se observa na convencional classificação: I - Trabalho como causa necessária; II - Trabalho como fator contributivo, mas não necessário; III - Trabalho como provocador de um distúrbio latente, ou agravador de doença já estabelecida (Jardim \& Glina, 2014).

Isto é, por ser multifatorial, a complexidade e dificuldade em se vincular o trabalho ao adoecimento psíquico, não existindo um consenso que tenha permitido uma classificação dos distúrbios psíquicos vinculados ao trabalho, existindo sim uma concordância da importância etiológica do trabalho, mas não a respeito do modo como se exerce a conexão (Merlo, 2014). 
De acordo com esses modelos teóricos o desenvolvimento de transtornos mentais e comportamentais relacionados ao trabalho está associado ao contexto laboral e a interação com o corpo e o aparato psíquico dos trabalhadores.

Ainda de acordo com Merlo (2014), entre os fatores geradores de sofrimento estão a falta de trabalho ou ameaça de perda do emprego; o trabalho desprovido da significação; as situações de fracassos; os ambientes que inibem a comunicação espontânea; os fatores relacionados ao tempo (ritmo, turno de trabalho, jornadas longas); a pressão por produtividade; a intensidade ou monotonia do trabalho executado; e a vivências de acidentes de trabalho traumáticos.

De forma geral, na ciência psicológica a explicação e intervenção sobre os fatores de saúde do trabalhador são "invisíveis" à físiologia e à bioquímica médicas. Esses fatores são ressaltados pelas particularidades dos casos, que se desdobram no contexto das teorias de estresse, psicodinâmica do trabalho e abordagem epidemiológica e/ou diagnóstica (Zanelli, Borges-Andrade \& Bastos, 2014).

Nessa perspectiva, considerando-se os diversos agravos à saúde mental do trabalhador, têm-se o estresse como ponto convergente que permeia o cotidiano das relações de trabalho e se destaca como temática central do estudo. Tornando-se factível que as situações ocupacionais inadequadas, às exigências entre o corpo e sobre as capacidades cognitivas e psíquicas no ambiente de trabalho podem ser geradoras das doenças mentais, à vista disso, devem ser investigadas as variáveis que podem influenciar o estresse laboral, depressão e ansiedade no intuito de colaborar com a compreensão desses fatores e para o desenvolvimento futuro de estratégias de prevenção, cuja meta é reduzir os danos causados pelo estresse, ansiedade e depressão no contexto laboral (Pereira, 2018).

Desta forma, considerando dados da literatura que apontam para a necessidade das maiores investigações que contribuam para a melhoria do transtorno emocional do trabalhador em geral, fundamentando esta pesquisa. Com isso, o estudo de Pereira (2018), foi tomado como base de justificativa para o presente artigo: pois, o autor supracitado, verificou variáveis que contemplam nível micro organizacional (variáveis psicológicas, neste caso, o assédio moral no trabalho e transtorno emocional) e nível macro organizacional (avaliado através da medida suporte organizacional (cf. Wagner III \& Hollenberck, 2000).

Nesse contexto, mesmo confiando que a organização, sua cultura e seus processos de gestão, tratam-se de um meio que tem o alvo em disciplinar o funcionário; ainda é bem perceptível que tais exercícios relativo à capacidade do gestor para que o diligente cumpra, o mais rápido possivel, a meta, mesmo que os valores organizacionais sejam contrariados e até desviados (Nascimento, 2014; Patriota, 2016; Formiga \& Souza, 2019); tais condições, poderão ser um espaço ideial para o surgimento comportamentos de assédio moral, através de manisfetaçoes como: a agressão verbal, a discriminção e arrogãncia funcional, chacotas, etc (cf. Pai, Sturbelle, Santos, Tavares, \& Lautert, 2018); manifestações estas, que se associação ao fenômeno da violência.

Sendo assim, neste contexto da violência, todos convergem para avaliação deste fenômeno no processo e ambiente de trabalho, pois são capazes de interferir na saúde, bem-estar e satisfação profissional, bem como, na qualidade de vida do trabalhador, com repercussões negativas diretas para a organização. Tais práticas, entendidas como mobbing, as quais, comportamentos contra a honra, (por exemplo, calúnia, a difamação e a injúria), contra a liberdade individual, (no caso do constrangimento ilegal e ameaça) e contra a dignidade sexual (Lima \& Souza, 2015).

O mobbing está associado diretamente a violência psicológica podendo afetar em experiências de estresse laboral, prejudicando a produtividade e o desempenho do trabalhador etc. É a partir da concepção desse termo (mobbing), reflete-se na possibilidade de se avaliar o assédio moral, pois, assumido quanto construto psicológico, poderá influenciar de forma sutil na manifestação de situações e comportamentos que humilham e/ou constrangem o funcionário no seu ambiente de trabalho e que, poderá ser atribuído - na perspectiva do gestor ou chefia - simplesmente, uma ação de cumprimento a regra e norma organizacional (Martins \& Ferraz, 2014). 
Desta maneira, o Assédio Moral no Trabalho não é um tema novo e já desde os anos 80, no século XX, a ciência psicológica aplicada ao trabalho tem se interessado pro ele; apesar de sua clareza conceitual, referindo-se a "exposição repetitiva e prolongada dos trabalhadores as situações de humilhação, vexame e constrangimento durante a jornada de trabalho" (Barreto, 2003, citado em Martins \& Ferraz, 2014, p.26), no que se refere a medida, este construto passou a se confundir, em sua categorização para uma mensuração psicológica, com diversos termos (por exemplo, assédio moral, bullying organizacional, atitudes de tirania, mobbing (molestar), ostracismo social, etc.) (cf. Lima \& Souza, 2015; Patriota, 2016; Nunes, Tolfo, \& Espinosa, 2018).

Com isso, partindo da definição destacada acima, é que Martins e Ferraz (2014), adaptaram e validaram, para o contexto brasileiro, uma medida destinada a avaliação do assédio moral, a qual foi capaz de avaliar a percepção do assédio moral, através de duas dimensões: assédio moral profissional (a qual atribui-se aos atos de violência no trabalho dirigidos pelo chefe aos subordinados que visam agredir o trabalhador em aspectos profissionais) e assédio moral pessoal (refere-se aos atos de violência no trabalho dirigidos pelo chefe aos subordinados que visam agredir o trabalhador em aspectos profissionais aos atos de violência no trabalho dirigidos pelo chefe aos subordinados que visam agredir o trabalhador em aspectos pessoais), os quais, são interdependentes.

De forma geral, esta pesquisa se inclui na natureza dos vínculos, forma e tipo de organização no mundo do trabalho, referindo-se às distintas sensibilidades de demandas e ofertas de condição social e humana frente a função de desenvolvimento, treinamento e implementação de programas de Recurso Humano contemporâneo nas organizações privadas e públicas associando a qualidade de vida pessoal e laboral (cf. Borges Andrade, Abbad \& Mourão, 2006; Bertoncello \& BorgesAndrade, 2015).

Condições, as quais, visa sua atuação em minimizar ou eliminar este sofrimento, favorecendo a saúde e não mais o adoecimento. Considerando estas reflexões, neste estudo, pretende-se quanto principal objetivo, verificar o poder preditivo da percepção do suporte organizacional e assédio moral no ambiente do trabalho sobre o transtorno emocional (ansiedade, depressão e estresse) em trabalhadores de organizações públicas e privadas.

\section{Metodologia}

Trata-se de um estudo descritivo, exploratório e correlacional, de abordagem quantitativa envolvendo trabalhadores em distintas organizações brasileiras. a importância em contemplar o enfoque quantitativo, refere-se à condição de uma coleta sistemática de informações numéricas, mediante condições de controle, bem como, analisar essas informações por meio de estatística (Polit \& Beck, 2011).

\section{Amostra}

No pacote estatístico GPower 3.1, foi realizado o cálculo da amostra; este programa tem o objetivo de verificar tanto a significância amostral quanto o poder estatístico (isto é, o teste de hipótese). Neste, tem-se, não apenas o 'n’ necessário para a pesquisa, mas, a identificação do tipo de cálculo a ser realizado (Faul, Erdfelder, Lang, \& Buchner, 2007) no presente estudo.

Para a coleta de dados neste estudo, considerando os seguintes critérios [probabilidade de 95\%, p < 0,05, magnitude do efeito amostral $(r \geq 0,50)$ e um padrão de poder hipotético $(\pi \geq 0,80)$ ], observou-se que, a necessidade de coletar uma amostra mínima de, aproximadamente, 150 trabalhadores de organizações públicas e privadas revelou-se suficiente (tendo como indicadores: $t \geq 1,98 ; \pi=0,97 ; \mathrm{p}<0,05$ ). Apesar do cálculo amostral considerar que o referido ' $\mathrm{n}$ ' de participantes era suficiente para o estudo; nesta pesquisa, devido a administração de uma coleta de amostra intencional, ao finalizar a coleta, fizeram parte desta, 212 trabalhadores brasileiros, de organizações públicas e privadas. 
No que diz respeito ao critério de inclusão considerou-se: estar empregado por mais de um ano e ativo no seu setor de trabalho, seja no Regime Jurídico Único - RJU, seja na Consolidação das Leis Trabalhistas - CLT, ser de qualquer área funcional onde será feita a coleta de dados e ter entre 20 e 40 horas de trabalho.

Sendo assim, no que se refere à caracterização da amostra, esta foi composta por, 212 trabalhadores, os quais: todos dos Rio Grande do Norte, com idade variando de 20 a 66 anos (Média = 39,49, d.p. =9,82), 62\% eram do sexo feminino, com 57\% apresentando uma renda econômica de salário-mínimo, $42 \%$ são funcionários de organizações privadas e um tempo de serviço variando de 1 a 37 anos (Média = 8,83, d.p. = 9,03).

\section{Instrumentos Para Coleta De Dados}

Um questionário foi administrado aos respondentes com as seguintes escalas de medidas:

Escala de Percepção de Suporte Organizacional (EPSO) - Trata-se de uma escala composta por 9 itens (SO1 = Esta empresa ignoraria qualquer reclamação de minha parte; $\mathrm{SO} 2$ = Esta empresa não considera meus interesses quando toma decisões que me afetam; $\mathrm{SO} 3$ = É possível obter ajuda desta empresa quando tenho um problema; SO4 = Esta empresa realmente preocupa-se com meu bem-estar; SO5 = Esta empresa estaria disposta a ampliar suas instalações para me ajudar a utilizar minhas melhores habilidades no desempenho do meu trabalho; SO6 = Esta empresa está pronta a ajudar-me quando eu precisar de um favor especial; SO7 = Esta empresa preocupa-se com minha satisfação com o trabalho; SO8 = Esta empresa preocupa-se mais com seus lucros do que comigo e $\mathrm{SO} 9$ = Esta empresa tenta fazer com que meu trabalho seja o mais interessante possível. Essa escala foi desenvolvida Eisenberger, Huntington, Hutchison, \& Sowa (1986) e adaptada e validada para o contexto brasileiro por Siqueira (1995).

Esta medida tem por objetivo avaliar o quanto as pessoas (que trabalham em organizações públicas e/ou privadas) percebem que a empresa tem uma preocupação com o bem-estar do empregado. Para mensurar o construto, o respondente deveria indicar a sua resposta, marcando com um X ou um círculo, em uma escala de sete pontos que variava de $1=$ discordo totalmente a 7 = concordo totalmente.

Em relação à confiabilidade da escala, no pioneiro estudo de Siqueira (1995) foi observado que essa medida apresentou um alfa de 0,86 , revelando uma consistência interna na mensuração do construto. Também, em uma amostra com trabalhadores brasileiros, tomando como base de orientação para análise psicométrica o estudo de Siqueira (2014), foi que Formiga, Fleury e Souza (2014), desenvolveram uma pesquisa para verificar, através da análise fatorial confirmatória, a consistência da estrutura fatorial da escala; estes autores, observaram indicadores psicométricos que garantiram a organização fatorial proposta pelo autor da EPSO ( $2 / \mathrm{gl}=1,42, \mathrm{RMR}=0,02, \mathrm{GFI}=0,99, \mathrm{AGFI}=0,97, \mathrm{CFI}=0,99, \mathrm{TLI}=0,99$ e $\mathrm{RMSEA}=$ $0,03)$.

Escala de percepção de assédio moral no mundo do trabalho (EPAMT): Trata-se de um instrumento que é composto por 24 itens (questões), desenvolvida por (Martins \& Ferraz, 2014); os itens focam nos atos de violência praticados no trabalho pelo chefe e/ou subordinados, tendo como objetivo agredir, de forma sutil ou direta, o trabalhador nos aspectos da sua profissão ou vida pessoal. O respondente deveria indicar sua resposta numa escala do tipo Likert, com variação que salienta à frequência da ocorrência de determinada situação (por exemplo, 1- nunca ou quase nunca; 2 - menos de uma vez ao mês; 3 ao menos uma vez ao mês; 4 - mais de uma vez ao mês; 5 - ao menos uma vez por semana; 6 - várias vezes por semana e 7 uma ou mais vezes ao dia).

De acordo com Martins \&Ferraz (2014), a EPAMT é distribuída em dois fatores: os itens 1, 2, 5, 6, 9, 10, 13, 15, 16, 17, 18, 19, 22 e 23 compõem o fator assédio moral profissional, referindo, aos atos de violência praticados pelos chefes com intenção de agredir os aspectos profissionais do subordinado; os itens 3, 4, 7, 8, 11, 12, 14, 20, 21 e 24, forma o fator sobre os atos de assédio moral pessoal, o qual, tem como foco a agressão ao trabalhador em relação aos seus aspectos pessoais. 
Escala de Ansiedade, depressão e estresse (em inglês, DASS-21): trata-se de um instrumento que foi desenvolvido por Lovibond e Lovibond (1995), constituído por um conjunto de três subescalas, respondida na escala tipo Likert, de 4 pontos, variando de $0=$ não se aplica totalmente a $4=$ aplica-se totalmente. Cada subescala é composta por 7 itens, destinados a avaliar os estados emocionais de depressão, ansiedade e estresse.

De acordo com os autores supracitados, a DASS foi desenvolvida com base no modelo tripartido, o qual, se organiza e estrutura em conceito e medida nos sintomas de cada transtorno destacado aqui; a saber: uma das dimensões, por exemplo, a depressão avalia a presença de sintomas que salientam afeto negativo, como inércia, falta de prazer e interesse/envolvimento, disforia, falta de auto-depreciação, desvalorização da vida e desânimo. A ansiedade, excitação do sistema nervoso autônomo; efeitos musculoesqueléticos; ansiedade situacional; experiências subjetivas de ansiedade. Finalmente, a subescala de estresse avalia dificuldade em relaxar; excitação nervosa; fácil perturbação/agitação; irritabilidade/reação exagerada e impaciência. Esta medida tinha como objetivo para autores que a desenvolveram (cf. Lovibond \& Lovibond, 1995) mensurar e diferenciar, ao máximo, os sintomas de ansiedade e depressão em sujeitos não clínicos.

A sua construção tomou-se como referência o modelo tripartido; este propõem uma estrutura fatorial com base no conceito e medida dos sintomas de ansiedade e depressão (cf. Patias, Machado, Bandeira, \& Dell'Aglio, 2016); sendo assim, é possível encontrar itens que com características da presença de afeto negativo (a saber: humor deprimido, insônia, desconforto e irritabilidade), destacando sintomas inespecíficos incluídos tanto na depressão quanto na ansiedade; e outros, que constituem estruturas que representam sintomas específicos para depressão (anedonia, ausência de afeto positivo); outros mais, referem-se aos sintomas específicos de ansiedade (tensão somática e hiperatividade) (Watson et al., 1995).

No Brasil, a DASS21 foi adaptada e validada por Machado e Bandeira (2013), apresentando indicados psicométricos de variando de 0,92 a 0,96 para as subescalas; Vignola e Tucci (2014) também observaram evidências de validade com os escores alfa de 0,86 a 0,92 para uma amostra clínica de adultos paulistas do sexo feminino.

Questionário Sociodemográfico - constitui em obter informações sobre os participantes, relativos ao vínculo de trabalho, sexo, idade e carga horária semanal de trabalho.

\section{Procedimento na administração do questionário e ética da pesquisa}

Todos os procedimentos adotados nesta pesquisa seguiram as orientações previstas na Resolução 016/2000 do Conselho Federal de Psicologia (ANPEPP, 2000).

Os instrumentos foram encaminhados aos respondentes através de um formulário eletrônico disponível online na página do Google Docs por um período de trinta dias. Ao solicitar a participação dos respondentes, foi informado que o objetivo do estudo seria o de avaliar a percepção dos profissionais relativamente ao ambiente de trabalho e a influência deste na sua saúde geral.

As pessoas que se mostraram interessadas e deram o seu consentimento em participar para fazer parte da amostra do estudo, foram esclarecidas quanto às suas respostas, as quais serão pessoais e sem interferência do administrador da pesquisa, assim, ao responder o instrumento, não haverá respostas certas ou erradas e elas serão tratadas de acordo com o que o sujeito pensou ao ler as questões apresentadas e indicou a sua resposta no instrumento apresentado.

Foi assegurado o anonimato das respostas, bem como, que as questões respondidas foram tratadas em seu conjunto de resposta e não na particularidade da resposta de cada sujeito. Apesar de se encontrar as instruções necessárias para que o questionário possa ser respondido, o pesquisador (com experiência prévia na pesquisa) colocou-se à disposição para esclarecimento sobre as dúvidas que surgirem; um tempo médio de 30 minutos foi suficiente para que a atividade pudesse ser concluída. 


\section{Análise de Dados}

Quanto à análise dos dados, utilizou-se o pacote estatístico SPSSWIN, em sua versão 24.0, para tabular os dados e realizar as análises estatísticas descritivas (média e desvio padrão, mediana), alfa de Cronbach, análise de regressão linear e anova.

\section{Resultados e Discussão}

Para o alcance do objetivo do estudo foram realizadas análises prévias para a comprovação da qualidade da amostra utilizada na pesquisa. As correlações entre as variáveis multivariadas atenderam aos critérios determinados por Tabachnick E Fidell (2001), considerando que a multicolinearidade ocorre quando duas ou mais variáveis independente possuem alto nível de similaridade para a explicação do fenômeno.

O teste de Kolmogorov-Smirnov (KS) utilizado para avaliação de amostras acima de 100 participantes, apresenta o real grau de desvio da normalidade e torna os resultados mais robustos e precisos para o estudo (cf. Miot, 2017). Neste sentido, essa análise feita para a constatação da amostra obteve resultado igual a $\mathrm{KS}=0,93, \mathrm{p}<0,45$.

No que se refere a variância comum do método (VCM) (common method variance), com base na proposta empírica de Podsakoff, MacKenzie e Podsakoff (2003), os quais, sugerem que, para a verificação do VCM, o teste de um fator de Harman nos dados coletados, o qual, ao ser gerado revelou um único fator com autovalor acima de 1,00, explicando $22 \%$ da variância, sendo abaixo do critério exigido pelos autores supracitados (isto é, 50\%) e que implica a inexistência da VCM.

A partir dessas análises preliminares, avaliou-se a consistência interna das escalas administradas, observando os seguires resultados (ver Tabela 1): na tabela abaixo, pode-se destacar que as escalas são confiáveis e que mensura as questões teóricas salientadas pelos construtos utilizados no estudo. Todos os alfas estiveram acima do critério estabelecido $(>0,70)$ quanto mínimo para a garantia a consistência das escalas de medida (Hutz, Bandeira, \& Trentini, 2015).

Tabela 1 - Escores dos alfas de Cronbach $(\alpha)$ das escalas aplicadas

\begin{tabular}{lccc}
\hline \multicolumn{1}{c}{ Construtos/ Variáveis } & & \multicolumn{2}{c}{ Alfas de Cronbach $(\alpha)$} \\
\cline { 2 - 4 } & Geral & $\begin{array}{c}\text { Variação } \\
\alpha_{\text {item exclú́do }}\end{array}$ & Estatística \\
\cline { 2 - 4 } & & $0,79-0,90$ & 18,25 \\
\hline $\begin{array}{l}\text { Escala de Percepção de Suporte } \\
\text { Organizacional (EPSO) }\end{array}$ & 0,88 & 15,23 \\
\hline $\begin{array}{l}\text { Escala de percepção de assédio moral no } \\
\text { mundo do trabalho (EPAMT) }\end{array}$ & 0,85 & $0,76-0,89$ & 0,01 \\
\hline $\begin{array}{l}\text { Escala de Ansiedade, depressão e estresse } \\
\text { (em inglês, DASS-21) }\end{array}$ & 0,97 & $0,96-0,98$ & 29,75 \\
\hline
\end{tabular}

Fonte: Autores

A partir dos indicadores alfas destacadas na Tabela 1, realizou-se uma análise de regressão linear a fim de avaliar quais são as variáveis que mais predizem o transtorno emocional (quanto pontuação total) e as suas especificidades (ansiedade, depressão e estresse). Inicialmente, considerou-se um modelo regressivo generalista, o qual, contemplou todas as variáveis propostas (percepção do suporte organizacional, assédio moral no trabalho e transtorno emocional).

Sendo assim, pode-se observar, na Tabela 2, que a percepção do suporte organizacional foi capaz de predizer, negativamente $(\beta=-0,30)$, o transtorno emocional em trabalhadores, enquanto o assédio moral no ambiente de trabalho, predisse positivamente $(\beta=0,27)$, todas significativas. Observou que tais predições revelaram que o modelo explicou $17 \%$ da amostra, tendo o VIF destacado que os preditores estão correlacionados, os quais, foram maiores do que 1 e menor do que 5 , com isso, não há multicolineariedade (ver Hair et al., 2009). 
Tabela 2 - Regressão linear do suporte organizacional e assédio moral (VI’s) sobre o transtorno emocional (VD).

\begin{tabular}{|c|c|c|c|c|c|}
\hline \multirow[t]{2}{*}{ Preditores } & \multicolumn{4}{|c|}{$\begin{array}{c}\text { Variável critério: } \\
\text { Transtorno emocional (pontuação total DASS-21) }\end{array}$} & \multirow[b]{2}{*}{ VIF } \\
\hline & $B$ & $S E$ & $\begin{array}{c}\text { Beta } \\
(\beta)\end{array}$ & $\begin{array}{c}\mathrm{t} \\
(>1,96)\end{array}$ & \\
\hline Intercepto & 21,82 & 3,31 & --- & $6,58 *$ & --- \\
\hline Percepção do suporte organizacional & $-0,52$ & $-0,15$ & $-0,33$ & $-3,42 *$ & 1,22 \\
\hline Assédio moral no ambiente de trabalho & 0,30 & 0,07 & 0,27 & $3,91 *$ & 1,22 \\
\hline Coeficiente de Regressão (R) & \multicolumn{5}{|l|}{0,43} \\
\hline Variância Explicada ( $\mathrm{R}^{2}$ ajustado $)$ & \multicolumn{5}{|c|}{$0,17(17 \%)$} \\
\hline Modelo & \multicolumn{5}{|c|}{$\mathrm{F}(2 / 211)=23,30, \mathrm{p}<0,001$} \\
\hline
\end{tabular}

Notas: *p < 0,01. Fonte: Autores.

Em seguida, procurou-se avaliar o quanto as VI's foram capazes de predizer as especificidades do transtorno emocional proposta pela medida DASS21 (isto é, estresse, ansiedade e depressão). Na Tabela 3, é possível observar que nas três especificidades do transtorno emocional, a percepção do suporte organizacional predisse, negativamente, o estresse $(\beta=-$ $0,24)$, ansiedade $(\beta=-0,20)$ e depressão $(\beta=-0,19)$; em relação ao construto do assédio moral no trabalho, este, revelou escores preditivos Betas $(\beta)$ positivos, sobre o estresse $(\beta=0,20)$, ansiedade $(\beta=0,17)$ e depressão $(\beta=0,35)$. Destaca-se também, os percentuais explicativos dos modelos preditivos: no modelo da predição do estresse houve $14 \%$ de variância, no modelo da ansiedade $9 \%$ e, por fim, no modelo da depressão $21 \%$.

Tabela 3 - Regressão linear do suporte organizacional e assédio moral (VI’s) sobre a dimensão do estresse, ansiedade e depressão (VD’s).

\begin{tabular}{|c|c|c|c|c|c|}
\hline \multirow[t]{2}{*}{ Preditores } & \multicolumn{4}{|c|}{$\begin{array}{l}\text { Variável critério: } \\
\text { Estresse }\end{array}$} & \multirow[b]{2}{*}{ VIF } \\
\hline & $B$ & $S E$ & $\begin{array}{c}\text { Beta } \\
(\beta)\end{array}$ & $\begin{array}{c}\mathrm{t} \\
(>1,96)\end{array}$ & \\
\hline Intercepto & 6,67 & 1,22 & --- & $5,45^{*}$ & --- \\
\hline Percepção do suporte organizacional & $-0,20$ & $-0,06$ & $-0,24$ & $-3,52 *$ & 1,22 \\
\hline Assédio moral no ambiente de trabalho & 0,08 & 0,03 & 0,20 & $2,84 *$ & 1,22 \\
\hline Coeficiente de Regressão (R) & \multicolumn{5}{|l|}{0,38} \\
\hline Variância Explicada ( $\mathrm{R}^{2}$ ajustado $)$ & \multicolumn{5}{|c|}{$0,14(14 \%)$} \\
\hline Modelo & \multicolumn{5}{|c|}{$\mathrm{F}(2 / 211)=17,52, \mathrm{p}<0,001$} \\
\hline \multirow[t]{2}{*}{ Preditores } & \multicolumn{4}{|c|}{$\begin{array}{c}\text { Variável critério: } \\
\text { Ansiedade }\end{array}$} & \multirow[b]{2}{*}{ VIF } \\
\hline & $B$ & $S E$ & $\begin{array}{c}\text { Beta } \\
(\beta)\end{array}$ & $\begin{array}{c}\mathrm{t} \\
(>1,96)\end{array}$ & \\
\hline Intercepto & 10,55 & 1,36 & --- & $7,75^{*}$ & --- \\
\hline Percepção do suporte organizacional & $-0,17$ & $-0,06$ & $-0,20$ & $-2,72 *$ & 1,22 \\
\hline Assédio moral no ambiente de trabalho & 0,08 & 0,03 & 0,17 & $2,39 *$ & 1,22 \\
\hline Coeficiente de Regressão (R) & \multicolumn{5}{|l|}{0,31} \\
\hline Variância Explicada ( $\mathrm{R}^{2}$ ajustado $)$ & \multicolumn{5}{|c|}{$0,09(9 \%)$} \\
\hline Modelo & \multicolumn{5}{|c|}{$\mathrm{F}(2 / 211)=1,33, \mathrm{p}<0,001$} \\
\hline \multirow[t]{2}{*}{ Preditores } & \multicolumn{4}{|c|}{$\begin{array}{c}\text { Variável critério: } \\
\text { Depressão }\end{array}$} & \multirow[b]{2}{*}{ VIF } \\
\hline & $B$ & $S E$ & $\begin{array}{c}\text { Beta } \\
(\beta)\end{array}$ & $\begin{array}{c}\mathrm{t} \\
(>1,96)\end{array}$ & \\
\hline Intercepto & 4,59 & 1,20 & --- & $3,83^{*}$ & --- \\
\hline Percepção do suporte organizacional & $-0,16$ & $-0,06$ & $-0,19$ & $-2,78^{*}$ & 1,22 \\
\hline Assédio moral no ambiente de trabalho & 0,15 & 0,03 & 0,35 & $5,20 *$ & 1,22 \\
\hline Coeficiente de Regressão (R) & \multicolumn{5}{|l|}{0,46} \\
\hline Variância Explicada ( $\mathrm{R}^{2}$ ajustado $)$ & \multicolumn{5}{|c|}{$0,21(21 \%)$} \\
\hline Modelo & \multicolumn{5}{|c|}{$\mathrm{F}(2 / 211)=28,60, \mathrm{p}<0,001$} \\
\hline
\end{tabular}

Notas: $* \mathrm{p}<0,01$. Fonte: Autores. 
Considerando que os resultados preditivos foram significativos, optou-se em realizar o cálculo da ANOVA one-way, em associação ao teste post-hoc de Sheffé, para avaliar a influência da variável da percepção do suporte organizacional, assédio moral no trabalho em relação ao transtorno emocional (estresse, ansiedade e depressão). É preciso salientar que o teste de Scheffé visa comparar os contrastes de médias significativas em uma função linear entre as variáveis (Hair et al., 2009). Sendo assim, para verificar os efeitos de tais variáveis, elas foram categorizadas em tercis, distribuídas nos seguintes níveis (1 $=$ baixo, $2=$ moderado e 3 = alto).

Desta forma, aplicada uma Análise de Variância Uni-variada, observaram-se que os resultados significativos estiveram para o efeito principal do suporte organizacional $\left(F_{(2,211)}=3,24, p<0.01\right)$, tendo o nível do baixo suporte organizacional apresentando maior escore médio em relação ao transtorno emocional; outro resultado significativo, de efeito direto ocorreu nono alto escore médio do assédio moral no trabalho, em relação ao transtorno emocional $\left(F_{(2,211)}=4,61, p<\right.$ 0.01). E por fim, efeito de interação entre percerpeção do suporte organizacional versus assédio moral no trabalho, explicando o transtorno emocional em trabalhadores, isto é, qual menor o suporte organizacional, maior o assedio moral no trabalho $\left(F_{(4,}\right.$ 211) $=2,61, p<0.01)$, os quais, influencia a saúde mental.

Considerando tais resultados, inicialmente, é possível destacar que as escalas utilizadas revelaram indicadores psicométricos confiáveis, o quais, permitem afirmar que os participantes da pesquisa compreenderam os conteúdos dos itens de cada construto, respondendo de forma que tal medida, conceitualmente, exigia; na tabela 1, tanto o cálculo do alfa de Cronbach quanto do ICC destacou que em todos os construtos, escores estatísticos foram maiores 0,70 (Pasquali, 2011; Hutz, Bandeira, \& Trentini, 2015); sendo assim, confiáveis. Desta maneira, ao salientar estas medidas comportamentais em questão, além de se mostrarem fidedignas, corroboram os achados de Formiga et al. (2021) sobre a escala de assédio moral, de Formiga, Freire e Fernandes (2019) sobre percepção do suporte organizacional e Formiga et. al., (2020) em relação a medida DASS21 que avalia ansiedade, depressão e estresse.

De forma geral, o transtorno emocional, seja em sua pontuação total (ver Tabela 2), seja nas suas especificidades (ansiedade, depressão e estresse - ver Tabela 3), tem sido cogitado quanto característica predominante na perspectiva explicativa das condições da saúde laboral (cf. Paula \& Formiga, 2021) ao considerar o domínio de saúde mental no ambiente de trabalho destinado a produtividade e qualidade funcional. Afinal, considerando que, excluindo as questões estruturantes da saúde mental, em termos de sua funcionalidade, nenhum problema de baixa aderência ao equilíbrio emocional na dinâmica de trabalho ocorreria no vazio interpessoal, mas, na via de mão-dupla organização-trabalhador; de fato, algum destes polos estaria evitando ceder para promover melhor funcionamento no desenvolvimento laboral.

O modelo preditivo que foi proposto permite compreender, justamente, o que foi expresso acima; de fato, um espaço laboral imbuído de violência psicológica seria capaz de causar prejuízo na produtividade e no desempenho do trabalhador por interferir na organização emocional deste, consecutivamente, em seu comportamento e interpessoalidade da dinâmica funcional do seu sistema de trabalho. Sendo assim, numa organização em que o assédio moral esteja presente, provavelmente, seja em sua sutiliza ou imperatividade dos comportamentos humilhantes e constrangedores (ver Martins \& Ferraz, 2014), a incidência de transtorno emocional (bem como, da ansiedade, depressão e estresse) poderá ser mais frequente.

Ao observar as variâncias explicadas (isto é, o $\mathrm{R}^{2}$ ajustado), nota-se um percentual hierárquico na sua apresentação de preditividade deste fenômeno e saúde mental. Com isso, mesmo com o construto assédio moral no ambiente de trabalho influencia na condição e saúde psíquica do trabalhador (ver Zanelli, Borges-Andrade \& Bastos, 2014), é destaque a dimensão da depressão, a qual, revelou maior percentual explicativo no modelo gerado, mas, também, na especificidade preditiva da variável do assédio (representado no Beta - cf. Tabela 3). Sendo a depressão (ou os traços depressivos) condição que conduz a pessoa à apatia, perda de interesse, ausência de ânimo e oscilações de humor etc. (American Psychiatric Association - DSM V, 
2014; Sena, 2014), com a influência do assédio moral no ambiente de trabalho, tal fenômeno poderá ser mais grave, já que o trabalhador estará sobre o 'poder' do seu gestor.

Nestes resultados é possível, também, sugerir uma proposta de modelo inibidor do transtorno emocional; nas tabelas 2 e 3, a variável suporte organizacional revelou uma predição negativa. Com tal construto sendo compreendido como uma condição de que forneça ao trabalhador entendimento e apercepção de que no seu ambiente de trabalho o gestor e a organização oferecem apoio e vínculo laboral para que o trabalho funcione melhor e mais saudável e com o menor dano possível a dimensão psicológica, social e física. (cf. Formiga et. al., 2020; Paula et. al., 2021).

Numa perspectiva, Formiga et al. (2020), em seu estudo com trabalhadores brasileiros, observaram que, quanto maior o suporte organizacional, melhor o investimento emocional (isto é, o capital psicológico positivo), maior a gestão do conhecimento (seja por parte do gestor ou pelo próprio trabalhador), consecutivamente, menor o transtorno emocional (ansiedade, depressão e estresse); noutra perspectiva, Paula et. al. (2021), numa pesquisa com trabalhadores que relataram ter vivido algum dano (psicológico, social ou físico) em seu ambiente de trabalho devido, justamente, a dinâmica laboral, foi observado que, quanto maior foi o escore médio na percepção de que a organização the dá apoio, cria vinculo e os tornas confiantes em sua função e com crível com a organização (isto é, eles tem um suporte organizacional), menor foi o escore médio nos suposto adoecimentos no ambiente de trabalho, pois, menor foi o escore no dano psicológico, social e físico. Ao abordar ambos os estudos, associados aos achados desta pesquisa, não apenas reconhecimento os pontos de práticas laborais que possam interferir na saúde do trabalhador, mas, também, direciona-se para o estabelecimento e manutenção de um programa de intervenção multiprofissional, apoiados nos recursos humanos da organização, visando prevenção, diagnóstico e promoção da saúde dos seus trabalhadores.

Ainda na Tabela 3, notou-se que os Betas de predição se associaram positivamente o assédio moral ao transtorno emocional (especificamente, a ansiedade, depressão e estresse), permitindo refletir que quando o funcionário sofre "exposição repetitiva e prolongada dos trabalhadores as situações de humilhação, vexame e constrangimento durante a jornada de trabalho" (Barreto, 2003, citado em Martins \& Ferraz, 2014, p.26), tal condição é capaz de causar uma dano emocional muito maior e que, provavelmente, seria causa de uma intervenção e tratamento psicológico. Sendo assim, é preciso uma maior atenção frente aos comportamentos em situação laborais de exigência e demandas, pois, poderá se apresente de forma sutil, num assédio no ambiente de trabalho.

Esses achados corroboram a reflexão de Freitas (2001) ao abordar este tema no início do século XXI, compreendendo a existência desse fenômeno tem sua base, de fato, no baixo suporte organizacional. Para esta autora, a situação em questão estaria associada as disputas de poder e busca de oportunidades para aumentar as arenas de influência, com as organizações apresentado, intrinsecamente, espaços de comportamento controlado, inibidoras de atitudes que possam prejudicar o seu melhor rendimento e a sua imagem. E que, mesmo tendo organizações que apresentem um discurso de humanização e democratização do mundo do trabalho, empowerment e de participação de todos os níveis no processo decisório, muitas empresas continuam a desenvolver práticas que favorecem a centralização de poder e o autoritarismo. Assim, uma administração por stress permite a naturalização de caminhos reprováveis, que servem de via de acesso para dar vazão à falta de escrúpulos de profissionais perversos, que retiram prazer de atos aviltantes e tirânicos (p. 18).

Ainda de acordo com a autora supracitada, a época da publicação do seu estudo, é possível verificar, um sem-número de táticas ou de técnicas que são usadas para forçar as pessoas consideradas indesejadas ou julgadas sem contribuição tão grande a dar, a fim de vencê-las pelo cansaço e levá-las a demitirem-se. Infelizmente, esse tipo de prática dos cortadores de custo tem ocorrido com bastante frequência, especialmente nos casos de fusão e aquisição, em que determinadas tarefas e posições são duplicadas. A ainda finaliza: "parece que um pouco de sangue dá um sabor mais picante à arena organizacional, 
existindo mesmo algumas pessoas que assumem o seu lugar no camarote para deliciar-se com os detalhes sádicos e sórdidos" (Freitas, 2001, p. 18).

Freire (2008, p. 1), destaca também, o quanto a qualidade de vida do funcionário depende, de forma direta, da qualidade no ambiente de trabalho. Sendo assim, neste ambiente, marcado por pressões pelo desempenho quantitativo e alcance de metas, e pela despersonalização do trabalhador - este tratado como objeto de produção - que acontece o denominado assédio moral, um processo de violência psicológica extremado contra o trabalhador, causando-lhe uma série de danos psicológicos. Mesquita et. al. (2017), pontua esta situação de forma bem clara, quanto apresenta em seu estudo que 2,47\% dos trabalhadores relataram já ter sofrido assédio moral e ainda mais, destaca a existência de uma correlação positiva entre assédio moral e sofrimento psíquico. Para o autor supracitado, apesar de identificar um número de trabalhadores bem menor que relataram sofrer assédio moral, comparado a estudos nacionais e internacionais, mesmo assim, pode-se salientar o quanto esta situação é causadora de um prejuízo à saúde mental dos assediados.

\section{Conclusão}

De forma geral, o presente estudo oferece uma reflexão não apenas da existência de uma dinâmica organização bastante adoecida, mas, apresenta caminhos para as práticas e políticas de RHs mais atentas e humanas. É fato que este estudo tem limites e acredita-se que este estaria associado a proposta de um modelo teórico associando os três construtos, já que no estudo preditivo abordado neste artigo tratou-se apenas de focar as direções e intensidade de variáveis explicassem o fenômeno do transtorno emocional em trabalhadores. Sendo assim, em estudos futuros, sugere a inclusão de uma variável que contemple à avaliação da cultural organização, bem como, comparem estes resultados com diferentes trabalhadores entre as capitais das regiões brasileiras.

\section{Referências}

American Psychiatric Association (2014). Diagnostic and Statistical Manual of Mental Disorders, Fifth Edition (DSM-V). American Psychiatric Association.

Associação Nacional de Pesquisa e Pós-Graduação em Psicologia - ANPEPP. (2000). Contribuições para a discussão das Resoluções CNS n0 196/96 e CFP N0 016/2000. http://www.anpepp.org.br/XIISimposio/Rel_ComissãoEticasobre_Res_CNS_e_CFP.pdf.

Bardini, C. (2017). Nexo causal: uma análise entre transtorno mental e trabalho. Revista Especialize, 13(01), 1-19.

Bertoncello, B., \& Borges-Andrade, J. E. (2015). Relações entre Suporte Organizacional e Saúde Mental do Trabalhador. Revisa Laborativa, 4(2), 85-102. http://ojs.unesp.br/index. php/rlaborativa.

Borges-Andrade, J. E., Abbad, G., \& Mourão, L. (Orgs.). (2006). Treinamento, desenvolvimento e educação em organizações e trabalho: Fundamentos para a gestão de pessoas. Artmed.

Brasil. (1990). Lei no 8.080, de 19 de setembro de 1990. Dispõe sobre as condições para a promoção, proteção e recuperação da saúde, a organização e o funcionamento dos serviços correspondentes e dá outras providências. <http://www.planalto.gov.br/ccivil_03/Leis/L8080.htm>.

Byrne, B. M. (2012). Structural equation modeling with Mplus: Basic concepts, applications, and programming. Taylor \& Francis/Routledge.

Conselho Nacional De Saude - CNS. (2012). Diretrizes e Normas Regulamentadoras de Pesquisas Envolvendo Seres Humanos.

Diógenes, L. C., Paschoal, T., Neiva, E. R., \& Meneses, P. P. M. (2016) Intenção de Rotatividade e Percepção de Suporte Organizacional em um Órgão Público Federal. Rev. Serv. Público Brasília 67(2), 147-172.

Eisenberger, R., Huntington, R., Hutchison, S., \& Sowa, D. (1986). Perceived organizational support. Journal of Applied psychology, 71(3), 500.

Estivalete, V., Andrade, T., Faller, L., Stefanan, A., \& Souza, D. (2016). Suporte social e suporte organizacional como antecedentes do bem-estar no trabalho: a perspectiva de colaboradores de uma empresa de logística ferroviária. DOI: 10.15600/1679-5350/rau.v14n2p31-56. Revista de Administração, 14(2), 31-56. http://dx.doi.org/10.15600/rau.v14i2.644

Faul, F., Erdfelder, E., Lang, A. G., \& Buchner, A. (2007). G* Power 3: A flexible statistical power analysis program for the social, behavioral, and biomedical sciences. Behavior research methods, 39(2), 175-191.

Fleury, A., \& Fleury, M. T. L. (2004). Estratégias empresariais e formação de competências: um quebra-cabeça caleidoscópio da indústria brasileira. (3a ed.), Atlas. 
Formiga, N. S., Silva, A. G. F., Silva, J. D., Firmino, T. T., Santos, S. X., Azevedo, F. L. B., \& Martins, J. G. F. . (2020). Transtorno emocional leve em trabalhadores: Verificação de um modelo teórico a partir do suporte organizacional, gestão do conhecimento e capital psicológico positivo. Research, Society and Development, 9(9), e580997597. https://doi.org/10.33448/rsd-v9i9.7597

Formiga, N. S., Franco, J. B. M., Oliveira, H. C. C., Araújo, L. A. S. C., Nascimento, F. S., \& Lima, E. A. S. A. (2021). Suporte organizacional e assédio moral no trabalho: Correlatos e diferenças entre funcionários da área de saúde e educação de um munícipio do Estado da Paraíba, Brasil. Psicologia E Saúde Em Debate, 7(1), 54-76. https://doi.org/10.22289/2446-922X.V7N1A5

Formiga, N., Fleury, L. F. O., \& Souza, M. A. (2014). Evidências de validade da escala de percepção de suporte organizacional em funcionários de empresa pública e privada. Estudos Interdisciplinares em Psicologia, 5(2), 60-76.

Formiga, N., Freire, B., \& Fernandes, A. (2019). Evidência métrica de construto e invariância fatorial da escala de percepção de suporte organizacional em trabalhadores brasileiros. Revista de Gestão e Secretariado, 10(2), 194-221. doi:https://doi.org/10.7769/gesec.v10i2.870

Freitas, M. E. (2001). Assédio moral e assédio sexual: Faces do poder perverso nas organizações. Revista de Administração de Empresas, 41(2),8-19.

Freire, P. A. (2008). Assédio moral e saúde mental do trabalhador. Trabalho, Educação e Saúde, 6 (2), 367-380. <https://doi.org/10.1590/S1981$77462008000200009>$.

Hair, J. F., Tatham, R. L., Anderson, R. E., \& Black, W. (2005). Análise Multivariada de dados. Bookman.

Jardim, S., \& Glina, D. (2014). Os diagnósticos dos transtornos mentais relacionados ao trabalho. In D. Glina \& L. Rocha (Eds.), Saúde mental no trabalho: Desafios e soluções (pp. 17-52). VK.

Lima, T. D. F., \& Souza, M. A. (2015). O Impacto do Mobbing sobre o estresse no trabalho. Estudos e Pesquisas em Psicologia, 15(2), 608-630.

Lovibond, P. P., \& Lovibond, S. H. (1995). The structure of negative emotional states: Comparison of the Depression Anxiety Stress Scales (DASS) with the fleck Depression and Anxiety Inventories. Behaviour Research and Therapy, 33(1), 335-342.

Martins, M. C. F., \& Ferraz, A. M. S. (2014). Assédio moral nas organizações. In: Siqueira, M. M. M. (Org.). Novas Medidas do Comportamento Organizacional: ferramentas de

Mcshane, S., \& Eglinow, M. (2013). Comportamento organizacional. AMGH Editora Ltda.

Merlo, A. R. C. (2014) Sofrimento psíquico e atenção à saúde mental. In: Merlo, A. R. C.; Bottega, C. G. \& Perez, K.V. Atenção à saúde mental do trabalhador: sofrimento e transtornos psíquicos relacionados ao trabalho. Evangraf.

Merlo, A. R. C., Bottega, C. G., \& Perez, K. V. (2014) Atenção ao sofrimento e ao adoecimento psíquico do trabalhador e da trabalhadora: cartilha para profissionais do Sistema Único de Saúde - SUS. Evangraf.

Mesquita, A. A., Silva, A. S., Bezerra, H. R., Fontinele, T. P., \& Neiva, Y. P. (2017). Assédio moral: impacto sobre a saúde mental e o envolvimento com trabalho em agentes comunitários de saúde. Revista Psicologia e Saúde, 9(1), 3-17. https://dx.doi.org/10.20435/pssa.v9i1.375

Nascimento, S. A. C. M. (2014). Assédio moral no ambiente do trabalho. Revista Ltr, 68 (8), 922-930.

Nunes, A. L. P. F. (2017). As pessoas como talentos na organização. 〈http://uniesp.edu.br/sites/_biblioteca/revist as/20170411123505.pdf〉

Pai, D. D., Sturbelle, I. C. S., Santos, C., Tavares, J. P., \& Lautert, L. (2018). Violência física e psicológica perpetrada no trabalho em saúde. Texto \& Contexto - Enfermagem, 27(1).

Patias, N. D., Machado, W. L., Bandeira, D. R., \& Dell'Aguio, D. D. (2016). Depression Anxiety and Stress Scale (DASS-21) - Short Form: Adaptação e Validação para Adolescentes Brasileiros. Psico-USF, 21 (3), 459-469.

Patriota, R. A. L. (2016). Assédio Moral em Instituições Bancárias da Capital Paraibana. Dissertação (Mestrado Profissional em Administração). Universidade Potiguar. Pró-Reitoria Acadêmica - Núcleo de Pós-Graduação

Paula, N. H. M. M., Formiga, N. S., Silva, A. K. L., Franco, J. B. M., Oliveira, H. C. C., Prochazka, G. L., Nascimento, R. L., Grangeiro, S. R. A., Valin, C. G. P., Beserra, T. K. P., \& Almeida, L. A. L. (2021). The better bond I have with my organization, the healthier I am! Correlates between organizational support and work-related injuries. Research, Society and Development, 10(6), e15710615323. https://doi.org/10.33448/rsd-v10i6.15323

Pereira, G, A. (2018). Correlatos entre suporte organizacional, capital psicológico e saúde geral de enfermeiros em um hospital público. Dissertação de Mestrado, Universidade Potiguar, UnP, Natal-Rio Grande do Norte, RN.

Polit, D.F., \& Beck, C.T. (2011) Fundamentos de Pesquisa em Enfermagem: Avaliação de Evidências para a Prática da Enfermagem. (7a ed.), Artmed.

Prado, C. G. (2005). Investigando a saúde mental: as relações entre suporte organizacional, satisfação e sentimentos de prazer e sofrimento no trabalho. Dissertação de Mestrado

Sá Junior, L. S. M. (2004). Desconstruindo a definição de saúde. Jornal do Conselho Federal de Medicina.

Sena, T. (2014). Manual diagnóstico e estatístico de transtornos mentais - DSM-5, estatísticas e ciências humanas: inflexões sobre normalizações e normatizações. Interthesis, 11 (2). ORG/10.5007/1807-1384.2014V11N2P96

Siqueira, M. M. M. (1995). Antecedentes do comportamento de cidadania organizacional: a análise de um modelo pós-cognitivo. Brasília, Tese (Doutorado) Universidade de Brasília. 
Research, Society and Development, v. 10, n. 7, e34010716720, 2021

(CC BY 4.0) | ISSN 2525-3409 | DOI: http://dx.doi.org/10.33448/rsd-v10i7.16720

Siqueira, M. M. M. (2003). Proposição e análise de um modelo para comportamentos de cidadania organizacional. Revista de Administração Contemporânea, 7 (spe),

165-184.

Siqueira, M. M. M. (2014). Novas medidas do comportamento organizacional: ferramentas de diagnóstico e de gestão. Porto Alegre: Artmed, 2014.

Sobrinho, F. R., \& Porto, J. B. (2012). Bem-Estar no Trabalho: um Estudo sobre suas Relações com Clima Social, Coping e Variáveis Demográficas.

Tabachnick, B. G. \& Fidell, L. S. (2001) Using Multivariate Statistics. (4a ed.), Allyn and Bacon.

Tagliapetra, O. M. (2015). A dinâmica das organizações modernas: flexibilidade, inovação e valorização dos talentos humanos. Revista Expectativa, 1(1), 1-9.

Van De Vijver, F., \& Leung, K. (1997). Methods and data analysis for crosscultural research. Thousand Oaks, CA: Sage Publications.

Vignola, R., \& Tucci, A. (2014). Adaptation and validation of the Depression Anxiety and Stress Scale (DASS) to Brazilian Portuguese. Journal of Affective Disorders, 155, 104-109.

Wagner III, J. A. \& Hollenbeck, J. R. (2000). Comportamento organizacional: Criando vantagem competitiva. São Paulo: Saraiva.

Watson, D., Clark, L. A., Weber, K., Assenheimer, J. S., Strauss, M. E., \& McCormick, R. A. (1995). Testing a tripartite model: II. Exploring the symptom structure of anxiety and depression in student, adult, and patient samples. Journal of Abnormal Psychology, 104(1), 15-25.

Zanelli, J. C. Borges-Andrade, J. E., \& Bastos, A.V.B. (Org.). (2014) Psicologia, organizações e trabalho no Brasil. (2a ed.), Artmed. xix, 615 p. 